\title{
Three Schools of Transformation Thinking \\ The Impact of Ideas, Institutions, and Technological Innovation on Transformation Processes
}

Uwe Schneidewind, Karoline Augenstein

\begin{abstract}
To identify the main drivers of transformation, it is helpful to identify the transformation perspectives of three specific schools of thought: idealist, institutional, and technological innovation. By differentiating among these schools of thought, a more informed transformation debate becomes possible, thereby increasing transformative literacy in academia and society.
\end{abstract}

Three Schools of Transformation Thinking. The Impact of Ideas, Institutions, and Technological Innovation on Transformation Processes | GAIA 25/2 (2016): 88-93 | Keywords: multi-level perspective, sustainability, transformation research, transformative literacy, transition

\begin{abstract}
In his article "Transformation" as a New Critical Orthodoxy, Ulrich Brand (2016) reflects on the current state of the transformation discourse. He analyses how an umbrella term like "transformation", which is not only a scientific concept but just as much part of a wider political narrative, can create a broadly shared consensus while at the same time spanning a variety of meanings and interpretations. Brand points out an important fault line in the transformation discourse and argues that "transformation" is either used as an analytical concept or with a strategic purpose. He criticizes that a merely strategic use of the term coupled with a focus on strategies of incremental change runs the risk of missing the deep structural causes of unsustainability and therefore argues for a more critical analytical approach that should complement and inform strategic transformation agendas. A major strength of the term "transformation" is that due to its "fuzziness" and varying conceptual understandings it can serve as a boundary object for different disciplinary perspectives as well as for the strategies and action frameworks of non-academic actors. As pointed out by Feola (2015), the fuzzy nature of a broad transformation concept gives it a strong metaphoric power and facilitates inter- and transdisciplinary research as well as strategic action, while at the same time conceptual ambiguity makes it easy for some actors
\end{abstract}

Contact: Prof. Dr. Uwe Schneidewind | Tel.: +49202 2492100 |

E-Mail: uwe.schneidewind@wupperinst.org

Dr. Karoline Augenstein | E-Mail: karoline.augenstein@wupperinst.org

both: Wuppertal Institute for Climate, Environment and Energy |

Döppersberg 19 | 42103 Wuppertal | Germany

(C) 2016 U. Schneidewind, K. Augenstein; licensee oekom verlag. This is an article distributed under the terms of the Creative Commons Attribution License (http://creativecommons.org/licenses/by/3.0), which permits unrestricted use, distribution, and reproduction in any medium,

provided the original work is properly cited. to co-opt the transformation agenda and actively impede radical societal change (Feola 2015). In line with Feola, and addressing Brand's concern about structural conditions and power relations as a major blind spot in the transformation debate, we argue that a better understanding of the underlying assumptions and theories of change shaping the transformation debate are important, especially with a view to fostering transformations in practice. We want to complement Brand's analysis with a more in-depth understanding of what kind of thinking is behind "transformation" and how this impacts strategic as well as analytical uses of the concept, both of which can be found in academia and beyond. In order to develop "transformative literacy" (Schneidewind 2013) that enables a comprehensive understanding of and orientation in complex transformation processes, it is necessary to map out and understand the different "worldviews and approaches, interests and estimates about potential entry and starting points" (Brand 2016, p. 24) in different schools of transformation thinking. It will also be shown how the different schools are interrelated, how they relate to different concepts of power (Partzsch 2015), and it will briefly be illustrated how such an approach may help increase reflexivity and awareness for structural conditions under which actual transformation processes, e.g., the energy transition (see below), are taking place.

\section{The Idealist, the Institutional, and the Technological Innovation School}

A broad approach allows for taking a bird's eye perspective across academic disciplines and theories. Attempts to structure the field of transformation research and first steps towards developing a comprehensive theory of change have been made by O'Brien and 
TABLE 1: Three schools of transformation thinking and their basic assumptions.

\begin{tabular}{|c|c|c|c|c|}
\hline $\begin{array}{l}\text { SCHOOL OF TRANS- } \\
\text { FORMATION THINKING }\end{array}$ & $\begin{array}{l}\text { CONCEPTION OF } \\
\text { HUMANKIND }\end{array}$ & $\begin{array}{l}\text { DRIVERS OF } \\
\text { CIVILIZATION }\end{array}$ & KEY PROPOSITION & $\begin{array}{l}\text { ASSOCIATED THEORIES } \\
\text { AND APPROACHES }\end{array}$ \\
\hline IDEALIST & $\begin{array}{l}\text { Humans are sense- } \\
\text { making, social and } \\
\text { communicative beings. }\end{array}$ & $\begin{array}{l}\text { ideas, } \\
\text { meaning }\end{array}$ & $\begin{array}{l}\text { Ideas rule the world. They drive human action } \\
\text { and shape the development of institutions } \\
\text { and technology. }\end{array}$ & $\begin{array}{l}\text { constructivism, social } \\
\text { system theories, theology }\end{array}$ \\
\hline INSTITUTIONALIST & $\begin{array}{l}\text { Humans are utility } \\
\text { maximizing beings. }\end{array}$ & institutions & $\begin{array}{l}\text { Societal development is shaped by institutions. } \\
\text { They facilitate the diffusion of new ideas and } \\
\text { shape processes of technological innovation. }\end{array}$ & $\begin{array}{l}\text { institutional theories in political } \\
\text { science and economics }\end{array}$ \\
\hline $\begin{array}{l}\text { TECHNOLOGICAL } \\
\text { INNOVATION }\end{array}$ & $\begin{array}{l}\text { Humans are routine- } \\
\text { dependent and } \\
\text { deficient beings. }\end{array}$ & technology & $\begin{array}{l}\text { Societal development depends on the contin- } \\
\text { uous expansion of the scope for human action } \\
\text { driven by technological innovation. }\end{array}$ & $\begin{array}{l}\text { innovation studies, science } \\
\text { and technology studies }\end{array}$ \\
\hline
\end{tabular}

Sygna (2013) who differentiate three spheres of transformation (practical, political, and personal) as an overarching framework for transformation research. Feola (2015) reviews different concepts of transformation and differentiates a descriptive and a prescriptive tradition (similar to Brand's analytical-strategic distinction). We want to bridge the gap between analytical and strategic uses, trying to identify basic assumptions across prescriptive and descriptive approaches. The aim is to offer a way of dealing with the "new critical orthodoxy" (Brand) that is characterized by "a radical problem diagnosis, promising far-reaching change, but also involving a rather incremental understanding of the processes and steps of social change in order to cope with the problems" (Brand 2016, p. 24).We suggest a distinction of transformation thinking that is characterized by three schools: the idealist, the institutional, and the technological innovation school (table 1). ${ }^{1}$

\section{The Idealist School - Ideas Rule the World}

The idealist school of transformation thinking includes all approaches built on the assumption that "ideas rule the world". Assuming that they are the essence and the foundation of every tangible aspect of human experience, representatives of an idealist school of transformation thinking assign a central role to ideas in processes of societal change as well. To explain and to analyze transformation we have to understand basic ideas (cultural values, dominant dogmas and world views) and how they impact societies. Similarly, if a transition to sustainability should be achieved, the necessary societal change processes must develop as the result of powerful ideas and discourses. ${ }^{2}$

Before dealing with the role of ideas for a transformation to sustainability, we need to clarify the general concept of "idea". We use it in the sense of "collective ideas" as defined by Legro: “(...) they are not simply individual conceptions that are shared or added together", but "have an intersubjective existence that stands above individual minds and is typically embodied in symbols, discourse, and institutions" (Legro 2000, p. 420). Max Weber has studied the impact of this type of ideas. In his book The Protestant Ethic and the Spirit of Capitalism (1930), he analyzes how religious ideas dominant in some strands of Protestantism (e.g., regarding divine predestination and salvation) have influenced social practices and behavior, in this case an ascetic and hard-working lifestyle, which fostered the development of capitalism. Weber argues that these religious ideas explain how Western capitalism evolved in its specific form and why it emerged in this form in Europe and not in other parts of the world where different belief systems are dominant. Abstracting from religion, his work amounts to the "formulation of a generalized theory of the role of nonempirical existential ideas in relation to action" (Parsons 1938, p. 659).

Assuming such a central role of ideas in shaping human behavior and societal development, what does this imply for processes of societal transformation, understanding past transitions and studying desired transitions to sustainability in the future? According to an idealist school of thought, collective ideas or shared beliefs are pivotal in change processes, they are the relevant determining factor, even though external pressures or certain events may trigger societal transformations. Therefore, similar circumstances faced by different societies or groups of people may lead to completely different development paths depending on the respective ideas commonly adhered to (Legro 2000).

Ideas can also be the starting point for transformation processes, because they determine "the very nature of the problems they [specific policy instruments] are meant to be addressing” (Hall 1993, p. 279), thus identifying a problem and a need to act in the first place. Braudel (1994) presents a historical example, explaining that the development of modern welfare states began with an "ideological phase" where concepts and ideas regarding the role of capital-

\footnotetext{
1 It should be noted that the three schools of transformation thinking identified in this article are not a definite or exhaustive list. Similar attempts of classification have been made before, e. g., by Geels (2010) analyzing seven different ontologies in the social sciences and their relation to the study of sustainability transitions, or Garud and Gehman (2012) discussing three metatheoretical perspectives on sustainability journeys (evolutionary, relational, durational). 2 As Baur (2005, p. 1078) puts it: "The term idealism in its broadest sense denotes the philosophical position that ideas (mental or spiritual entities) are primary and lie at the very foundation of reality, knowledge, and morality, while non-ideal entities (such as physical or material things) are secondary and perhaps even illusory".
} 
ism, poverty and an exploited proletariat began to emerge. Protest and political measures followed suit only after this phase of newly emerging ideas.

Unsurprisingly, this type of idealist thinking can also be found in recent studies on sustainability transitions. For instance, Geels (2010) identifies structuralism and interpretivism/constructivism as two important strands in the field of transition studies. According to a structuralist ontology, "large-scale changes start with new ideas, ideologies and discourses" and, similarly, interpretivist or constructivist ontologies assume that "(t)ransitions gather pace when socio-cognitive processes converge ('closure') into shared views and agreement about the best way forward" (Geels 2010, p. 499 f.). Both of these ontological positions can be grouped under the idealist school of transformation thinking as outlined here. ed rationality, evolving preferences and the ability to learn (Coase 1960, North 1981). This deviation from basic assumptions in standard economics, e.g., stable preferences and market equilibrium, has been carried further in the field of new institutional economics emerging in the late 1990s (Coase 1998, North 1990, Ostrom 2005, Williamson 2000). A "new institutionalism" has also emerged in political science during the second half of the 1990s (cf. Hall and Taylor 1996).

Even though there are differences in definitions and focus across the social sciences, institutions can broadly be defined as "webs of interrelated rules and norms that govern social relationships, comprise the formal and informal social constraints that shape the choice-set of actors" (Nee 2001, p. 8). Formal (laws and regulations) and informal rules (social conventions) function as

\section{Collective ideas or shared beliefs are pivotal in change processes, they are the relevant determining factor, even though external pressures or certain events may trigger societal transformations.}

Research approaches that can be classified as following this school are those that are predominantly interested in cultural values, dominant paradigms and world views shaping human actions at different levels - ranging from local social practices, societies as a whole, the economic system or even international governance at a global level. An important role is attributed to civil society and social movements, which are often early advocates of new ideas taking shape (e.g., feminist or ecological social movements).

\section{The Institutional School - Institutions are Enablers of Societal Change}

The institutional school of transformation thinking includes all approaches that emphasize the role of institutions in shaping society. Institutions and their role have emerged as an important theme throughout the social sciences. The institutional school is closely related to idealist thinkers and builds on their work. For instance, so-called old or historical institutionalist approaches draw their basic insights from Karl Marx and Max Weber, studying the formal and informal rules and procedures in modern nation states. The roots of institutionalist thinking can thus be found in the processes of modern nation-building characterized by the emergence of professional, bureaucratic forms of organizing societies in states (Campbell 1998). Since then, the concept of institution has seen a remarkable career throughout sociology, historical science, political science and international relations, economics and organization theory (Nee 2001). As a prominent example, institutional economics focus on markets and economic transactions shaped by institutional conditions and interactions between individuals and organizations that are characterized by bound- a coordinating mechanism, by translating collectively accepted norms into guidelines for individual behavior, and by providing means of controlling and enforcing compliance with these rules. In that sense, institutions are the basic "incentive structure" for economic and political activity. They embody basic ideas of what is acceptable behavior, the range of possible or acceptable solutions, and of the overall legitimacy of specific policy measures. Due to their longevity, institutions also create stability in the sense that they facilitate credible expectations in recurring situations, thus reducing uncertainty (Campbell 1998, Mayntz and Scharpf 1995, Nee 2001, Richter and Furubotn 1996). According to such a broad definition, institutions can take the form of overall societal norms and values, codified regulatory frameworks as well as rules defined by private actors or organizations - as long as they have reached a certain level of diffusion and are binding in some way. They can thus be found at various levels and they structure human behavior in all societal sub-systems (Schneidewind et al. 1997).

According to an institutional school of thought, societal change and transformation depend on the institutional set-up and the specific formal and informal rules shaping society. Especially informal rules are in turn influenced by overarching ideas, but according to this school of thinking, societal transitions can most likely be achieved by creating suitable institutional framework conditions. A specific conceptualization of institutions that has influenced the study of sustainability transformations, and especially the multi-level perspective on transitions (MLP), is Giddens' duality of structure (1984). Giddens argues that structure, i.e., rules and resources, are simultaneously shaping action and are themselves being shaped by actors. Institutions are those rules and resources that are valid across space and time, or "the more endur- 
ing features of social life" (Giddens 1984, p. 24). In the MLP, these enduring features are captured in the concept of the regime: the deep structure that is made up of rule systems and that lies behind the stability and path-dependency of socio-technical systems (Geels 2002, 2011). Due to the duality of structure, such stability does not per se preclude change, but shows how institutions are at the same time constraining and enabling human action - and thus also the potential for transformation. That makes institutions the central starting point for achieving sustainability transitions via effective policies, suitable organizational architectures and rule systems, which are then followed by (and enable) changing social practices, new ideas and cultures, and sustainability-oriented technological innovation processes and markets.

\section{The Technological Innovation School - Technological Progress Drives Modern Societies}

The technological innovation school of transformation thinking is the youngest of the three schools of thought. While idealist approaches can be traced back to ancient philosophers and institutionalist approaches can be linked to the age of enlightenment where traditional feudal systems decayed and modern states began to develop, the technological innovation school has its roots in the $20^{\text {th }}$ century. Only in the aftermath of industrialization, in an age of technological progress closely connected to increasing economic welfare, is it plausible for new technologies and innovation to become a central element in thinking about what drives societies as a whole.

The impact of technology and technological progress on societies and their economic systems was studied by Kondratieff (1926), analyzing the interlinkages between technological and economic development. He discovered "long waves" of development, with the beginning of each wave tied to a groundbreaking technological invention. Such a wave typically spans a period of roughly 50 years and when it begins to decline, new inventions are stimulated and will eventually trigger the next long wave. Schumpeter (1939) built on Kondratieff's work and further elaborated the interlinkages between technological progress and economic development. His famous concept of "creative destruction" illustrates the major importance associated with technological inventions, which once they are turned into marketable innovations - can lead to radical change and initiate a new long wave altering the entire economic system.

Apart from the accelerating technological developments observed during the $20^{\text {th }}$ century, the increasing importance attributed to technological innovation as a driver of human civilization can be explained as the outcome of more general societal trends: collective ideas and institutional framework conditions in Western societies began to converge and stabilize during the second half of the $20^{\text {th }}$ century, and Western ideas and institutions also turned global after the fall of the Iron Curtain. Basic norms and values, e.g., related to democratic systems, individualism and participation in society, as well as institutional architectures of mar- ket-based capitalistic economies began to spread around the globe. In this situation, innovation in technologies and infrastructures increasingly become recognized as the central driver of societal change (Inglehart and Welzel 2009, Norgaard 1994).

Many research approaches that can be counted among the technological innovation school have been key sources for sustainability transitions or transformation research. For instance, building on Schumpeter amongst others, evolutionary economics began to develop as a distinct field of research. Evolutionary economics focus on drivers and barriers for the emergence of innovations, on technological regimes and trajectories at the level of firms and industrial sectors (e.g., Dosi 1982, Nelson and Winter 1982) or at the level of "techno-economic paradigms" shaping societies as a whole (Freeman and Perez 1988). Since these approaches were essential to the emergence of transition studies, radical technological innovations play an important role in this young field of research (Geels 2010). The technological innovation school can be shown to have impacted a "socio-technical co-evolution", e. g., the interlinkages between technological development and related processes of institutional and organizational change. Especially research on technological innovation systems (Carlsson and Stankiewicz 1991) plays a role. It observes the emergence of radical innovations that contribute to sustainability-oriented change in socio-technical systems as well as development processes of green technologies.

\section{The Three Schools of Transformation Thinking Compared}

None of the three schools of transformation thinking denies, in principle, the relevance of central aspects in the other schools, but each assigns a dominant role to the specific aspect central in their own approaches. Considering the complexity of current challenges and the debates about suitable strategies for achieving sustainable development, an important first step is to reflect on underlying assumptions of different approaches, making them transparent by, for instance, understanding their relation to the different schools of transformation thinking presented here.

\section{Transformation and the Question of Power}

In order to fully capture the dynamics in transformation processes and to identify the leverage points for fostering currently ongoing transformation processes, it is important to understand how the different perspectives on transformation and power structures are interlinked. With regard to Brand's argument that the current transformation debate fails to adequately address societal power structures, it is interesting to see how the three schools of transformation thinking can be connected with recent attempts to conceptualize the role of power in transformation processes: Partzsch (2015) has drawn a distinction between three ideal-typical conceptions of power in this context (table 2, p. 92). 
TABLE 2: Linking different concepts of power (Partzsch 2015) to the three schools of transformation thinking

\begin{tabular}{lll} 
SCHOOL OF TRANSFORMATION THINKING & POWER CONCEPT & EXPLANATION \\
\hline IDEALIST & power with & Power of shared ideas enables joint action, e.g., of NGOs and activists. \\
\hline INSTITUTIONALIST & power over & Institutions define political, economic and societal power structures. \\
\hline TECHNOLOGICAL INNOVATION & power to & New technologies enable niche actors to challenge existing regimes.
\end{tabular}

First, the concept of power with focuses on cooperation and learning, where power emerges as the concerted action of a community that is built around shared beliefs and social learning processes. This conception of power is closely connected to basic assumptions of an idealist school of transformation thinking, where the power of ideas motivates joint action towards a shared goal.

Second, the concept of power to focuses on resistance and empowerment and thus adds a perspective of confrontation and conflict. Power to assumes an adversarial other, against which a group of actors needs to be empowered or empower itself to affect change. This perspective is dominant in research on social movements or environmental NGOs that try to change existing societal structures. It also fits well with the technological innovation school of transformation thinking, where niche innovations are needed to challenge existing system structures and open windows of opportunity for change against a resisting regime.

Third, power over focuses on coercion and manipulation, where powerful actors can influence and determine the actions of less powerful groups, shape political agendas and public discourses, and decide on the range of possible or acceptable solutions to problems. This power concept fits well with the institutionalist school of transformation thinking and its emphasis on the role of political or market institutions that determine system dynamics and provide a structural framework for action.

Different schools of transformation thinking can help understand different aspects of transformation processes, just like Partzsch's three concepts of power are not three alternative perspectives on the same phenomenon, but rather complementary explanations of different aspects of the same phenomenon. The three schools of transformation thinking offer a similarly integrated perspective on the basic assumptions regarding the main drivers of transformation. Such multidimensional approaches are needed, "because it is unlikely that only one kind of causal factor or mechanism can explain entire transition processes" (Geels 2011, p. 38).

\section{The German Energy Transition - Understanding the Transformation Process}

The example of the German energy transition serves as a brief illustration how each of the three schools of transformation thinking can explain key elements of this transformation process, and a combined perspective shows why this specific case has become an example of a (so far) successful transformation. The power of ideas has led to the emergence of a strong social movement against nuclear power in Germany in the 1970s and 1980s. This was part of a broader environmental debate and the idea of an energy transition formed around visions of societal change and a future postfossil culture. This was an important basis for institutional change and moral ideas have eventually been translated into political action, such as the Electricity Feed-In Act (Stromeinspeisungsgesetz, 1991) and the Renewable Energy Act (Erneuerbare-Energien-Gesetz or EEG, 2000). The scale and scope of the energy transition today has been realized through technological innovation in the field of renewable energy technologies. Early pioneers and innovators were motivated by the ideas of the environmental movement and visions of a decentralized, renewables-based energy system. Later on, the changing institutional framework conditions in politics and markets led to an upscaling of these niche innovations and increasing economic feasibility.

\section{Mobility: Barriers of Change}

It is the interplay of ideas, institutions and technological innovation that drives successful transformation processes, and it is important to gain a better understanding of each of these dimensions to learn about drivers and barriers for actual change. Lessons may be learned for the transition towards sustainable mobility, as a case that is notoriously difficult as compared to the energy transition. Regarding the transport sector, some actors hope that a sustainability transition can be achieved based on technological innovation. Strategies revolve around inventing a technological fix that combines the reduction of emissions and the achievement of economic success with an innovative vehicle while preserving established mobility patterns. Public discourse as well as research focus mainly on the development and diffusion of alternative fuels and drive technologies (e.g., through financial incentives for buying electric cars). In contrast to the energy transition, the success of green technological innovations in transport remains limited, arguably because a shared vision of sustainable mobility and of a post-fossil mobility culture is lacking. Institutions, infrastructure and cultural aspects, such as the meaning attributed to cars, need to be addressed for achieving sustainability-oriented change as well as the power structures involved. While in the case of the energy transition the power of ideas and the success of critical social movements have made it increasingly difficult for the vested interests of energy companies to be pushed through politically, the opposite is true for the case of (auto)mobility. 


\section{Conclusion}

Brand has clearly pointed out that the current transformation debate is characterized by a critical imbalance between very radical problem diagnoses - based on natural science perspectives - and much less radical proposals for addressing these problems in a failure to deal with the structural conditions of societal change. As a way of dealing with this discrepancy we propose an analytical separation of three schools of transformation thinking. Such a differentiation can also make explicit the biases in academic disciplines and scientific approaches, leading to the observed disregard for societal power relations and power asymmetries. The three schools of transformation thinking can thus also strengthen the critical function of social-ecological sustainability research (Jahn 2014).

\section{References}

Baur, M. 2005. Idealism. In: New dictionary of the history of ideas. Edited by M. Horowitz. Detroit, MI: Thomson Gale. 1078-1082.

Brand, U. 2016. "Transformation" as a new critical orthodoxy. The strategic use of the term "transformation" does not prevent multiple crises. GAIA 25/1: 23-27.

Braudel, F. 1994. A history of civilizations. New York: Penguin.

Campbell, J. L. 1998. Institutional analysis and the role of ideas in political economy. Theory and Society 27/3: 377-409.

Carlsson, B., R. Stankiewicz. 1991. On the nature, function and composition of technological systems. Journal of Evolutionary Economics 1/2: 93-118.

Coase, R. 1960. The problem of social cost. Journal of Law and Economics 3:1-44.

Coase, R. 1998. The new institutional economics. American Economic Review 88/2: $72-74$.

Dosi, G. 1982. Technological paradigms and technological trajectories. Research Policy 11: 147-162.

Feola, G. 2015. Societal transformation in response to global environmental change: A review of emerging concepts. Ambio 44: 376-390.

Freeman, C., C. Perez. 1988. Structural crises of adjustment, business cycles and investment behaviour. In: Technical change and economic theory. Edited by G. Dosi, C. Freeman, R. Nelson, G. Silverberg, L. Soete. London: Pinter. 38-66.

Garud, R., J. Gehman. 2012. Metatheoretical perspectives on sustainability journeys: Evolutionary, relation and durational. Research Policy 41/6: 980-995.

Geels, F.W. 2002. Technological transitions as evolutionary reconfiguration processes: A multi-level perspective and a case-study. Research Policy 31/8-9: 1257-1274.

Geels, F.W. 2010. Ontologies, socio-technical transitions (to sustainability), and the multi-level perspective. Research Policy 39/4: 495-510.

Geels, F.W. 2011. The multi-level perspective on sustainability transitions: Responses to seven criticisms. Environmental Innovation and Societal Transitions 1: 24-40.

Giddens, A. 1984. The constitution of society. Outline of the theory of structuration. Cambridge, MA: Polity Press.

Hall, P.A. 1993. Policy paradigms, social learning, and the state: The case of economic policymaking in Britain. Comparative Politics 25/3: 275-296.

Hall, P. A., R. C. R. Taylor. 1996. Political science and the three new institutionalisms. MPIFG Discussion Paper 96/6. Cologne: Max-Planck-Institut für Gesellschaftsforschung.

Inglehart, R., C. Welzel. 2009. Development and democracy: What we know about modernization today. Foreign Affairs March: 33-41.

Jahn, T. 2014. Wissenschaft für eine nachhaltige Entwicklung braucht eine kritische Orientierung. GAIA 22/1: 29-33.

Kondratieff, N. D. 1926. Die langen Wellen der Konjunktur. Archiv für Sozialwissenschaft und Sozialpolitik 56: 573-609.
Legro, J.W. 2000. The transformation of policy ideas. American Journal of Political Science 44/3: 419-432

Mayntz, R., F. W. Scharpf. 1995. Steuerung und Selbstorganisation in staatsnahen Sektoren. In: Gesellschaftliche Selbstregelung und politische Steuerung. Edited by R. Mayntz, F.W. Scharpf. Frankfurt am Main: Campus. 9-38.

Nee, V. 2001. Sources of the new institutionalism. In: The new institutionalism in sociology. Editd by M.C. Brinton, V. Nee. Stanford: Stanford University Press.

Nelson, R. R., S. G. Winter. 1982. An evolutionary theory of economic change. Cambridge, MA: Harvard University Press.

Norgaard, R. B. 1994. Development betrayed. The end of progress and a coevolutionary revisioning of the future. New York: Routledge.

North, D. C. 1981. Structure and change in economic history. New York: W.W. Norton.

North, D. C. 1990. Institutions, institutional change and economic performance. Cambridge, UK: Cambridge University Press.

O'Brien, K., L. Sygna. 2013. Responding to climate change: The three spheres of transformation. In: Proceedings of the conference Transformation in a Changing Climate. Edited by University of Oslo. 16-23.

Ostrom, E. 2005. Doing institutional analysis: Digging deeper than markets and hierarchies. In: Handbook of new institutional economics. Edited by C. Menard, M. Shirley. Berlin: Springer. 819-848.

Parsons, T. 1938. The role of ideas in social action. American Sociological Review 3/5: 652-664.

Partzsch, L. 2015. Kein Wandel ohne Macht - Nachhaltigkeitsforschung braucht ein mehrdimensionales Machtverständnis. GAIA 24/1: 48-56.

Richter, R., E. Furubotn. 1996. Neue Institutionenökonomik. Tübingen: Mohr.

Schneidewind, U. 2013. Transformative Literacy. Gesellschaftliche Veränderungsprozesse verstehen und gestalten. GAIA 22/2: 82-86.

Schneidewind, U., P. H. Feindt, H.-P Meister, J. Minsch, T. Schulz, J. Tscheulin. 1997. Institutionelle Reformen für eine Politik der Nachhaltigkeit: Vom Was zum Wie in der Nachhaltigkeitsdebatte. GAIA 6/3: 182-196.

Schumpeter, J.A. 1939. Business cycles. A theoretical, historical and statistical analysis of the capitalist process. New York: McGraw-Hill.

Weber, M. 1930. The protestant ethic and the spirit of capitalism. London: Routledge.

Williamson, O.E. 2000. The new institutional economics: Taking stock, looking ahead. Journal of Economic Literature 38/3: 595-613.

Submitted February 16, 2016; revised version accepted May 31, 2016.

Uwe Schneidewind

Born 1966 in Cologne, Germany. Study of business administration at University of Cologne and HEC/Paris. 1998 to 2010 professor for business administration at the University of Oldenburg (2004 to 2008 president). Since

2010 president of the Wuppertal Institute for Climate,

Environment and Energy and professor for Sustainable Transition Management at the University of Wuppertal. Member of the German Advisory Council on Global Change (WBGU) and member of the Board of Directors of GAIA.

Karoline Augenstein

Born 1985 in Heidelberg, Germany. BA in European Studies at the University of Maastricht and MA in Sustainability Economics and Management at the University of Oldenburg. 2014 PhD. Research fellow at the Wuppertal Institute for Climate, Environment and Energy.

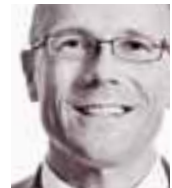

Research areas: sustainable system innovations, sustainability transitions research, concepts of transdisciplinary research for sustainability. 